\title{
A Simple and Rapid Approach for Removing Citrinin while Retaining Monacolin K in Red Mold Rice
}

\author{
Chun-Lin Lee, ${ }^{\dagger}$ Wen-Pei Chen, ${ }^{\dagger} \mathrm{JyH}^{-J}$ Ye Wang, ${ }^{*}$ And Tzu-Ming Pan ${ }^{*}, \dagger$ \\ Institute of Microbiology and Biochemistry, National Taiwan University, Taipei, Taiwan and \\ Department of Biotechnology, Tajen University, Pingdon, Taiwan, Republic of China
}

\begin{abstract}
Monascus species-fermented red mold rice (RMR) has been regarded as a popular hypolipidemic functional food because it contains monacolin $\mathrm{K}$, an inhibitor of de novo cholesterol synthesis. However, the safety of RMR is always an issue because citrinin is present in RMR and is reported to be hepatotoxic and nephrotoxic. The present study was therefore to develop a postprocess to remove citrinin yet retain monacoln $\mathrm{K}$ in the RMR preparation. We found that phosphate-ethanol extraction was effective for the removal citrinin, yet it could retain monacolin $\mathrm{K}$, because the former was more hydrophilic than the latter in phosphate-ethanol solution. Ethanol, phosphate, and extraction time were optimized as factors of response surface methodology (RSM). It was found that the optimal RSM condition was $45 \%$ ethanol, $1.5 \%$ phosphate, and extraction for 70 min. Under this optimal condition, $91.6 \%$ citrinin was removed and $79.5 \%$ monacolin $\mathrm{K}$ was retained in the final RMR.
\end{abstract}

KEYWORDS: Monascus; red mold rice; detoxification; monacolin; citrinin; response surface methodology (RSM)

\section{INTRODUCTION}

The Monascus species has been used as a traditional food fungus in Eastern Asia for several centuries. Since the worthy secondary metabolite, monacolin $\mathrm{K}$, was found to inhibit the biosynthesis of cholesterol, Monascus fermented rice, known as red mold rice (RMR), has gradually developed as a popular functional food for treating hypolipidemia (1). Although monacolin $\mathrm{K}$ from RMR was found over twenty years ago and has been regarded as a popular hyperlipidemic functional food in current years, the safety of RMR is always a concern because of the hepatotoxicity and nephrotoxicity of citrinin (2). Citrinin $\left[\mathrm{C}_{13} \mathrm{H}_{14} \mathrm{O}_{5}\right.$; IUPAC, (3R,4S-trans)-4,6-dihydro-8-hydroxy-3,4,5trimethyl-6-oxo-3H-2-benzopyrane-7-carboxylic acid] is one of the mycotoxins produced by fungi that belong to Penicillium, Aspergillus, and Monascus species. It is toxic, especially to the liver and kidney, and was suspected to be a carcinogen leading to renal tumors (2). RMR containing a high citrinin level is unacceptable even though it contains a higher concentration of monacolin K. Both monacolin $\mathrm{K}$ and citrinin are polyketide derivatives. Therefore, they are unavoidably produced at the same time (3-5). However, the citrinin expression mainly depends on the original character, such as gene expression of the Monascus strain (6). Previous studies always investigated the culture condition and the method for reducing citrinin formation while retaining monacolin $\mathrm{K}$ formation in $\operatorname{RMR}(5,7)$.

\footnotetext{
* Author to whom correspondence should be addressed. Telephone: + 886-2-3366-4519; fax: +886-2-2362-7044; e-mail:tmpan@ ntu.edu.tw.

${ }^{\dagger}$ National Taiwan University.

* Tajen University.
}

Although altering culture condition was able to decrease the citrinin formation of Monascus species, the optimal culture condition found in previous studies was not certain to be valid for every Monascus species. Other than altering the citrinin expression of Monascus species, developing a postprocess to remove citrinin from RMR should be an important rescue method. Furthermore, each RMR has similar physical characteristics such as water solubility; therefore, the postprocess may be widely useful for removing citrinin from each RMR. When the cost and convenience are considered, this study provides a simple and rapid method for the removal of citrinin while retaining monacolin $\mathrm{K}$ in RMR.

Citrinin is regarded as a prevalent mycotoxin of Aspergillus and Penicillium species and has been found to cause serious contamination in many cereals $(8-10)$. As far as the removal and the detoxification of citrinin are concerned, many physical and chemical methods have been proposed in previous studies such as heating and hydrogen peroxide treatments (11-13). Although many approaches have been proven to remove or detoxify citrinin in cereals, a method that could remove citrinin yet retain monacolin $\mathrm{K}$ in RMR has not been proposed in previous studies. To establish a suitable method for RMR, various physical or chemical methods including heating treatment, hydrogen peroxide treatment, alkaline solution extraction, diluted ethanol extraction, and phosphate-ethanol extraction were used to test the effect in this study.

The selection of these methods was based on the level of monacolin $\mathrm{K}$ and on the effectiveness of removing citrinin. Citrinin is unstable at high temperature, unlike monacolin $\mathrm{K}$ (13). Hydrogen peroxide treatment was proven to be able to break citrinin (11), but the damage to monacolin $\mathrm{K}$ was not 
Table 1. Process Variables and Levels in the Three Variables/Three Levels Response Surface Design

\begin{tabular}{lcccc}
\hline & & \multicolumn{3}{c}{ coded-variable level } \\
\cline { 3 - 5 } \multicolumn{1}{c}{ variable } & symbol & -1 & 0 & 1 \\
\hline ethanol concentration (\%) & $X_{1}$ & 35 & 40 & 45 \\
phosphate concentration (\%) & $X_{2}$ & 0.5 & 1.0 & 1.5 \\
extraction time (min) & $X_{3}$ & 30 & 50 & 70
\end{tabular}

Table 2. Process Variables and Levels in the Three-Factor/Three-Levels Response Surface Design of Secondary Metabolites Experiment

\begin{tabular}{llcc}
\hline & \multicolumn{3}{c}{ independent variables (coded-level) } \\
\cline { 2 - 4 } runs & ethanol (\%) & phosphate $(\%)$ & extraction time (min) \\
\hline 1 & $45(1)$ & $1.5(1)$ & $50(0)$ \\
2 & $45(1)$ & $0.5(-1)$ & $50(0)$ \\
3 & $35(-1)$ & $1.5(1)$ & $50(0)$ \\
4 & $35(-1)$ & $0.5(-1)$ & $50(0)$ \\
5 & $45(1)$ & $1(0)$ & $70(1)$ \\
6 & $45(1)$ & $1(0)$ & $30(-1)$ \\
7 & $35(-1)$ & $1(0)$ & $70(1)$ \\
8 & $35(-1)$ & $1(0)$ & $30(-1)$ \\
9 & $40(0)$ & $1.5(1)$ & $70(1)$ \\
10 & $40(0)$ & $1.5(1)$ & $30(-1)$ \\
11 & $40(0)$ & $0.5(-1)$ & $70(1)$ \\
12 & $40(0)$ & $0.5(-1)$ & $30(-1)$ \\
13 & $40(0)$ & $1(0)$ & $50(0)$ \\
14 & $40(0)$ & $1(0)$ & $50(0)$ \\
15 & $40(0)$ & $1(0)$ & $50(0)$ \\
\end{tabular}

reported. In addition, the hydrophilic ability of citrinin would be increased under alkaline condition (14), which might be used to extract citrinin selectively. Monacolin K, with its higher hydrophobic ability, easily dissolves in ethanol, methanol, chloroform, and ethylacetate. However, citrinin, with its weaker hydrophilic ability, dissolves in ethanol, methanol, and chloroform under acidic conditions and is dissolved in water under

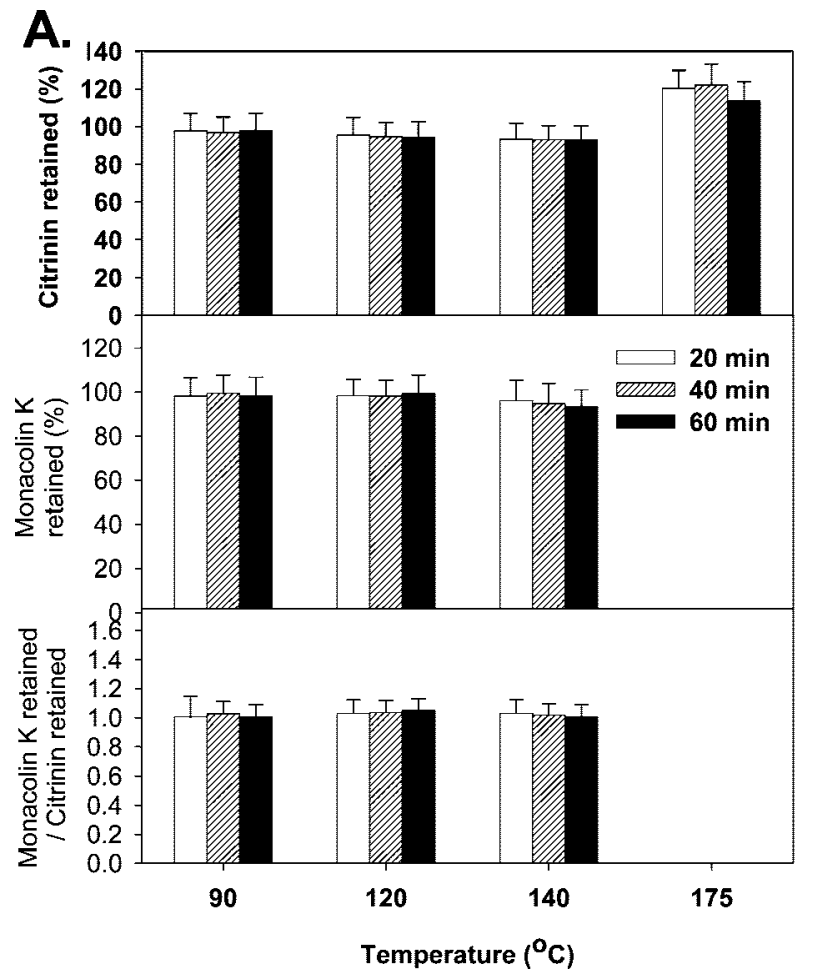

alkaline conditions. On the basis of the different levels of hydrophobic ability, citrinin is easier to extract than monacolin $\mathrm{K}$ by diluted ethanol. However, this study found that acidic conditions would lead to increased hydrophobic ability in monacolin $\mathrm{K}$ more so than in citrinin. Therefore, acidic ethanol is likely to extract more citrinin than monacolin K. According to the above principle, these methods have more potential for removing citrinin while retaining monacolin $\mathrm{K}$ in $\mathrm{RMR}$. The optimal condition of the most suitable extraction methods would be further investigated using response surface methodology to obtain the optimal RMR with higher monacolin K and lower citrinin levels.

\section{MATERIALS AND METHODS}

Chemicals. Monacolin K (mevanolin), citrinin, sodium hydrogen peroxide, sodium bicarbonate, sodium acetate, Tris-base, phosphate, and hydrogen peroxide were purchased from Sigma Chemical Co. (St. Louis, MO, USA). LC grade acetonitrile was purchased from Merck Co. (Darmstadat, Germany). Tryptone, yeast extract, peptone, malt extract, PDA broth, and Bacto-agar were purchased from Difco Co. (Detroit, MI, USA). Ethanol (95\%) was purchased from Taiwan Tobacco and Liquor Corporation (Taipei, Taiwan).

Preparation of Red Mold Rice. The long-grain rice purchased from a local supermarket in Taiwan was used for RMR production under solid state cultivation. Monascus purpureus NTU 568 was used to prepare RMR using the method proposed in our previous study (4). After fermentation, red mold rice was dried at $50{ }^{\circ} \mathrm{C}$ for $24 \mathrm{~h}$ and then milled into powder with a blender at room temperature.

Heating Treatment. Dry heating was carried out according to the following procedure. One gram of RMR powder was heated in the oven, which was set at $90,120,140,160$, or $175^{\circ} \mathrm{C}$ for $20,40,60$, or 80 min. Wet heating treatment was carried out according to the procedure listed in a previous study (15). One gram of RMR and $10 \mathrm{~mL}$ of distilled water were combined in a $50 \mathrm{~mL}$ glass vial. After the vial was sealed, the mixture was heated using oven set at $90,120,140,160$, or $175^{\circ} \mathrm{C}$

B.

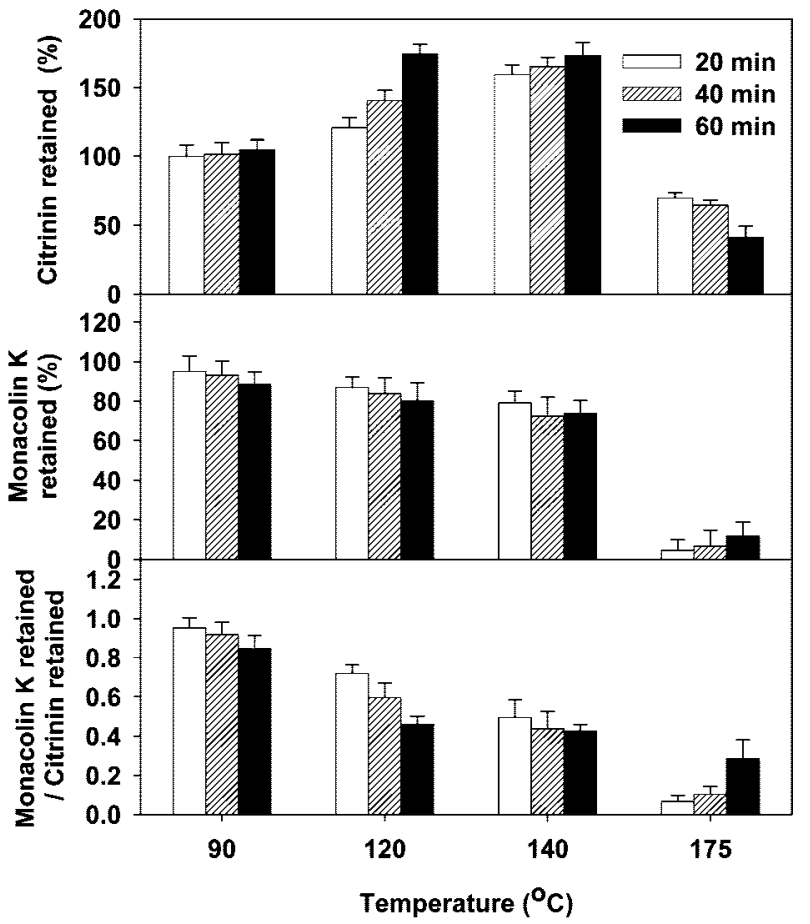

Figure 1. The effect of heating treatment on monacolin $\mathrm{K}$ retained, citrinin retained, and the $\mathrm{M} / \mathrm{C}$ ratio of RMR. (A) Dry-heating treatment. (B) Wetheating treatment. One gram of RMR with or without $10 \mathrm{~mL}$ of distilled water was placed in a $50 \mathrm{~mL}$ glass vial and heated in an oven. Wet RMR powder was dried using a freezing dryer for determination of monacolin $\mathrm{K}$ and citrinin levels $(n=3)$. 
A.

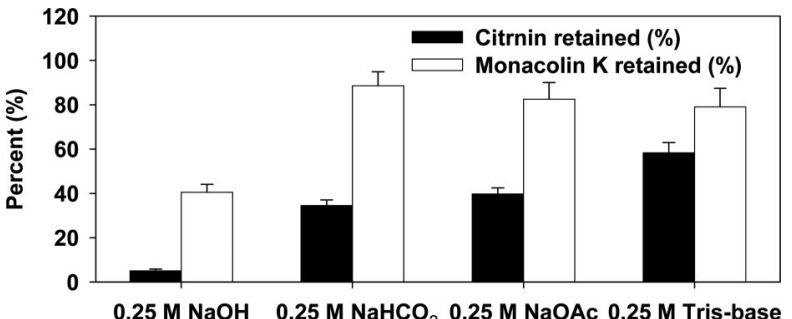

$0.25 \mathrm{M} \mathrm{NaOH} \quad 0.25 \mathrm{M} \mathrm{NaHCO}_{3} \quad 0.25 \mathrm{M} \mathrm{NaOAc} 0.25 \mathrm{M}$ Tris-base

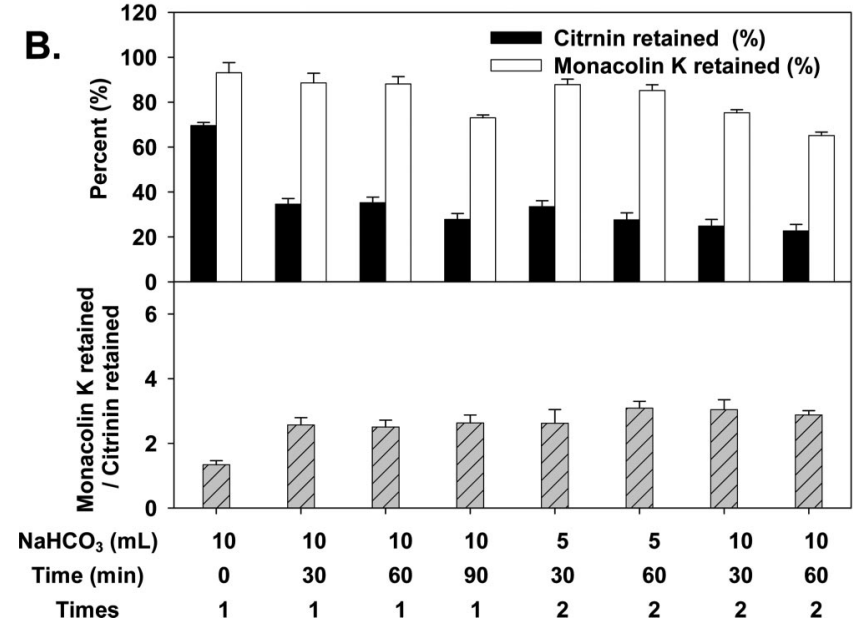

Figure 2. The effect of alkaline solution extraction on monacolin $\mathrm{K}$ retained, citrinin retained, and the M/C ratio of RMR. (A) Extraction with various alkaline solutions. (B) Extraction at various conditions with $0.25 \mathrm{M}$ sodium bicarbonate. The alkaline solution was used to extract $1 \mathrm{~g}$ of RMR powder at $30{ }^{\circ} \mathrm{C}$ for $30 \mathrm{~min}$. After extraction, the extracted solution was removed, and then $10 \mathrm{~mL}$ of distilled water was added to remained RMR powder. The $\mathrm{pH}$ value was adjusted to 4.5 , and the sample was evaporated to dryness for determination of monacolin $\mathrm{K}$ and citrinin levels $(n=3)$.

for $20,40,60$, or $80 \mathrm{~min}$. Wet RMR powder was then dried in a freezing dryer. Monacolin $\mathrm{K}$ and citrinin retained in RMR were extracted and analyzed using high-performance liquid chromatography (HPLC).

Alkaline Solution Extraction. Various alkaline solutions, including sodium hydrogen peroxide, sodium bicarbonate, sodium acetate, or Trisbase, were used to extract $1 \mathrm{~g}$ of RMR powder at $30{ }^{\circ} \mathrm{C}$ for $30 \mathrm{~min}$, respectively. After extraction, the extracted solution was removed, and then $10 \mathrm{~mL}$ of distilled water was added to the remaining RMR powder. The $\mathrm{pH}$ value of the RMR solution was adjusted to 4.5 , and the mixture was evaporated to dryness. Monacolin $\mathrm{K}$ and citrinin retained in RMR were extracted, and the concentrations of both materials were further determined by HPLC.

Detoxification with Hydrogen Peroxide. A $0.5 \mathrm{~g}$ portion of RMR powder was treated with $2.5 \mathrm{~mL}$ of a hydrogen peroxide solution $(0.05$, $0.1,0.25,0.5,1$, or $2 \%, \mathrm{v} / \mathrm{v}$ ) at room temperature for 20,40 , or 60 min. After treatment, the hydrogen peroxide solution was removed. Retained RMR powder was then washed with distilled water 2-3 times. RMR powder was then collected and evaporated to dryness after centrifugation (7000 $\mathrm{g}$ for $15 \mathrm{~min}$ ). Monacolin $\mathrm{K}$ and citrinin retained in RMR were extracted and were similarly determined using HPLC.

Extraction with Diluted Ethanol Solution. A $1 \mathrm{~g}$ portion of RMR powder was extracted with $10 \mathrm{~mL}$ of diluted ethanol solution $(10,20$, or $30 \%, \mathrm{v} / \mathrm{v}$ ) at 37,50 , or $60{ }^{\circ} \mathrm{C}$ for 20,40 , or $60 \mathrm{~min}$. RMR powder was evaporated to dryness after removing the diluted ethanol solution. Monacolin K and citrinin retained in RMR were extracted and analyzed using HPLC.

Extraction with Phosphate-Ethanol Solution. A $1 \mathrm{~g}$ portion of RMR powder was extracted with $10 \mathrm{~mL}$ of phosphate-ethanol solution including $0.25,0.5,0.75$, or $1.0 \%$ phosphate $(\mathrm{w} / \mathrm{v})$ and $20,30,40$, or $50 \%$ ethanol at $65{ }^{\circ} \mathrm{C}$ for $30 \mathrm{~min}$. RMR powder was evaporated to dryness after removing phosphate-ethanol solution. Monacolin K and citrinin retained in RMR were extracted and analyzed using HPLC.

Determination of Monacolin $\mathrm{K}$ and Citrinin Levels. A $1 \mathrm{~g}$ portion of dried RMR powder was extracted with $10 \mathrm{~mL}$ of ethanol at $65{ }^{\circ} \mathrm{C}$

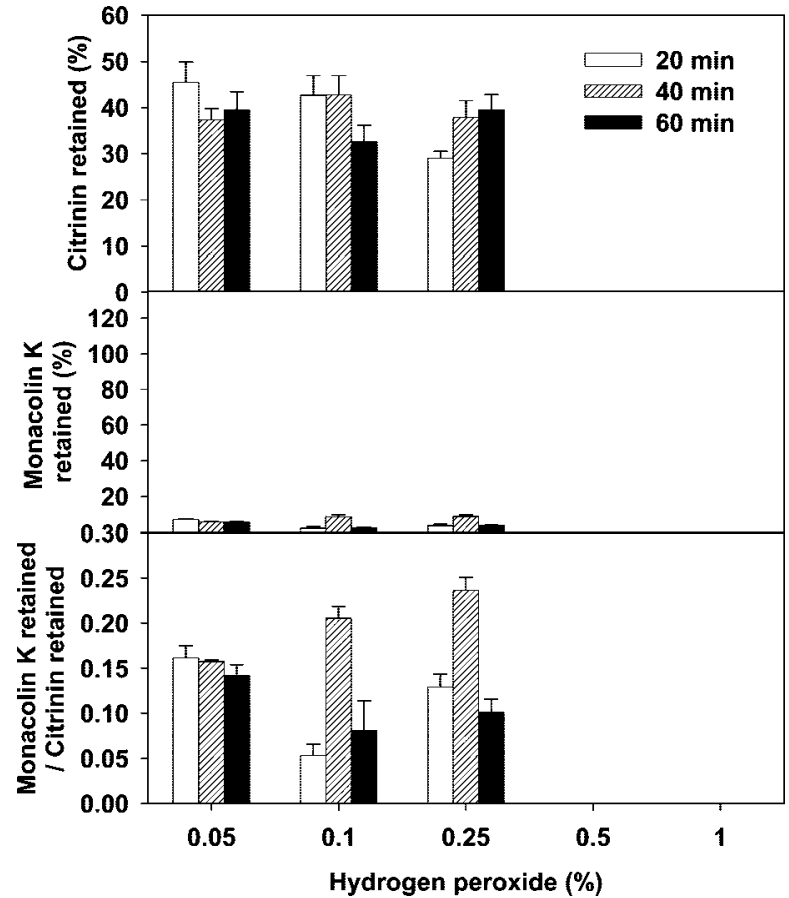

Figure 3. The effect of various concentrations and treatment times of hydrogen peroxide on monacolin $\mathrm{K}$ retained, citrinin retained, and the $\mathrm{M} / \mathrm{C}$ ratio of RMR. A $0.5 \mathrm{~g}$ portion of RMR powder was treated with 2.5 $\mathrm{mL}$ of a hydrogen peroxide solution. After treatment, the hydrogen peroxide solution was removed. The remaining RMR powder was washed with distilled water 2-3 times. RMR powder was collected and evaporated to dryness for the determination of monacolin $\mathrm{K}$ and citrinin levels after centrifugation $(7000 \mathrm{~g}$ for $15 \mathrm{~min}, n=3$ ).

for $30 \mathrm{~min}(16)$. The extracts $(10 \% \mathrm{w} / \mathrm{v})$ were further filtered with a $0.45 \mu \mathrm{m}$ filter and were analyzed by HPLC. HPLC analysis was performed according to the method previously described (16) and was carried out on an HPLC system PU2089 plus (Jasco Co., Tokyo, Japan) in this study. A Discovery $\mathrm{C}_{18}$ column, $25 \mathrm{~cm} \times 4.6 \mathrm{~mm}$ i.d., $5 \mu \mathrm{m}$ (Bellefonte, PA, USA), was used as the analytical column. The mobile phase, consisting of $45 \%$ water, $55 \%$ acetonitrile, and $0.5 \%$ trifluoroacetate, was eluted at a flow rate of $1.0 \mathrm{~mL} / \mathrm{min}$. Total monacolin $\mathrm{K}$ was detected using a UV detector UV2075 plus (Jasco Co.) set at 238 $\mathrm{nm}$. For citrinin analysis, the fluorescence detector FL-1 (Rainin Co, Wobum, MA, USA) was set at a wavelength of $330 \mathrm{~nm}$ and an emission wavelength of $500 \mathrm{~nm}$. The $\mathrm{R}^{2}$ values of monacolin $\mathrm{K}$ and citrinin were 0.9914 and 0.9978 , respectively. The retaining percentage of monacolin $\mathrm{K}$ and citrinin was calculated as follow:

The retaining percentage $(\%)=$ (retaining concentration/original concentration) $\times 100 \%$.

Design of Experiments. To identify the optimum condition, a Box-Behnken design (17) was selected. The crucial factors considered in this study included ethanol concentration $\left(\mathrm{X}_{1}\right)$, phosphate concentration $\left(\mathrm{X}_{2}\right)$, and extraction time $\left(\mathrm{X}_{3}\right)$. These factors, and the level at which the experiments were carried out, are shown in Tables $\mathbf{1}$ and $\mathbf{2}$. A total of 15 runs with center points were generated. The central point of the design arrangement used in this study was an ethanol concentration of $40 \%$, a phosphate concentration of $1.0 \%$, and an extraction time of 50 min.

Response Surface Methodology. The analysis of data was carried out using response surface regression (RSREG) in statistical analysis system (SAS, Cary, NC, USA). A second-order model was employed to fit the data individually for the responses $\mathrm{Y} 1$ (monacolin $\mathrm{K}$ retained, $\%)$, Y2 (citrinin retained, \%), and Y3 (monacolin $\mathrm{K}$ retained/citrinin retained, $\mathrm{M} / \mathrm{C}$ ratio) by the general mode (18), with three factors, each coded factor was in the range of $-1,0,+1$.

$\mathrm{Y}=\mathrm{A}_{0}+\mathrm{A}_{1} \mathrm{X}_{1}+\mathrm{A}_{2} \mathrm{X}_{2}+\mathrm{A}_{3} \mathrm{X}_{3}+\mathrm{A}_{12} \mathrm{X}_{1} \mathrm{X}_{2}+\mathrm{A}_{13} \mathrm{X}_{1} \mathrm{X}_{3}+\mathrm{A}_{23} \mathrm{X}_{2} \mathrm{X}_{3}$ $+\mathrm{A}_{11} \mathrm{X}^{2}{ }_{1}+\mathrm{A}_{22} \mathrm{X}_{2}{ }_{2}+\mathrm{A}_{33} \mathrm{X}^{2}{ }_{3}$. 
A.

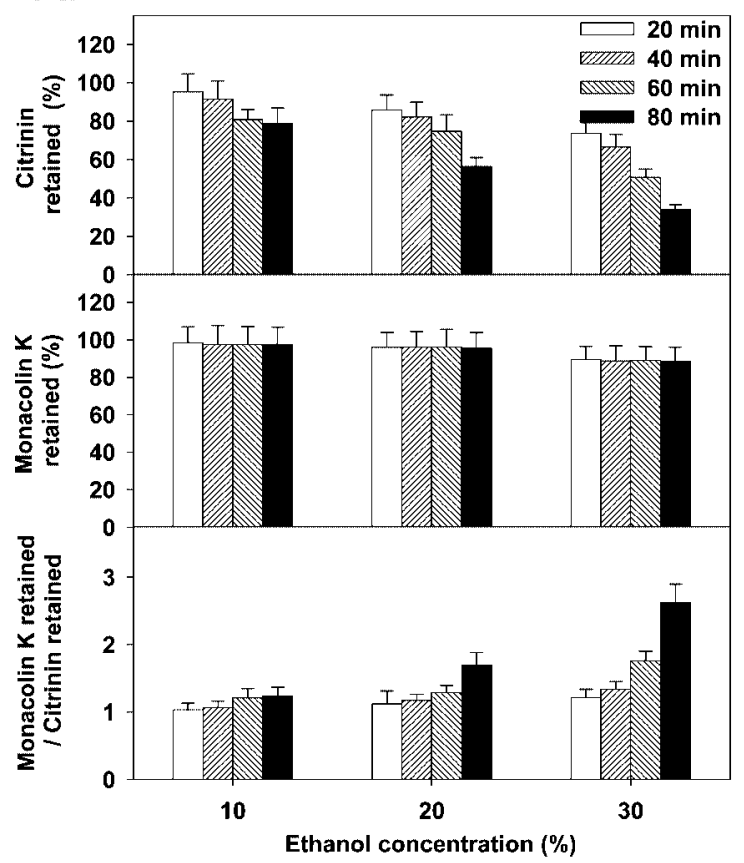

B.

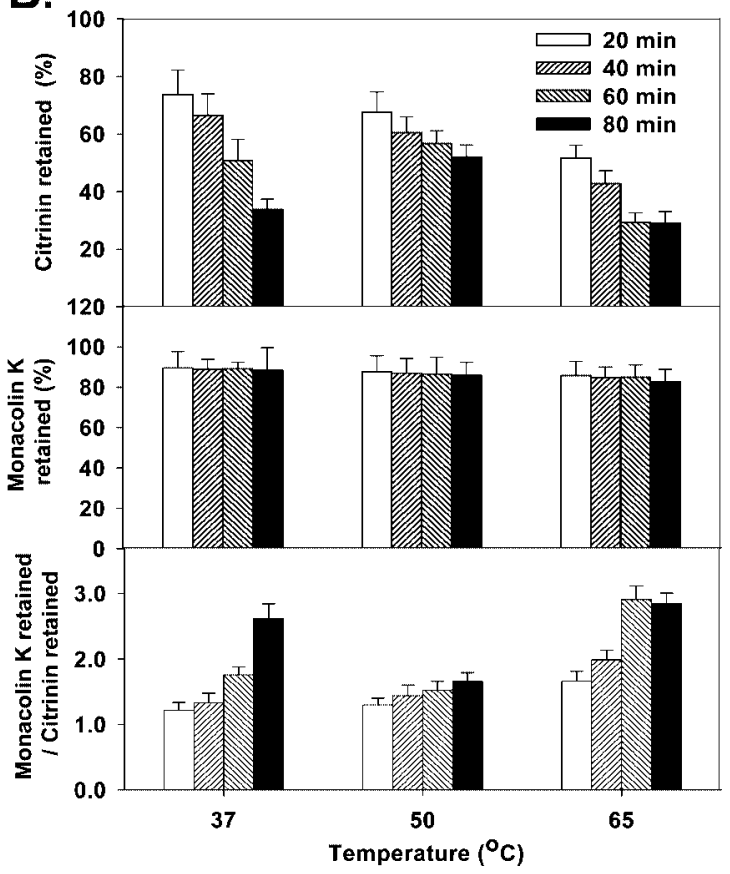

Figure 4. The effect of diluted ethanol extraction on monacolin $\mathrm{K}$ retained, citrinin retained, and the M/C ratio of RMR. (A) Extraction with various ethanol concentrations. (B) Extraction with $30 \%$ ethanol at various temperatures. A $1 \mathrm{~g}$ portion of RMR powder was extracted with $10 \mathrm{~mL}$ of a diluted ethanol solution. RMR powder was evaporated to dryness for determination of monacolin $\mathrm{K}$ and citrinin levels after removing the diluted ethanol solution $(n=3)$.

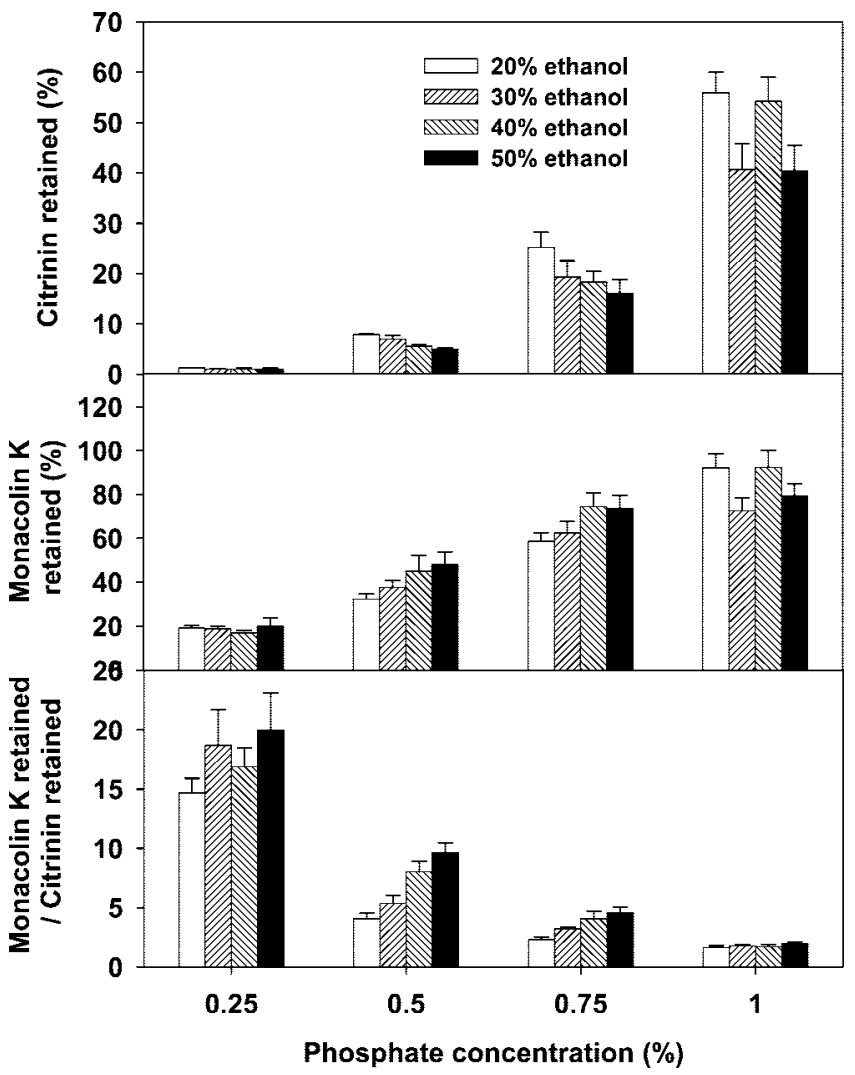

Figure 5. The effect of the phosphate-ethanol extraction on monacolin $\mathrm{K}$ retained, citrinin retained, and the M/C ratio of RMR. A $1 \mathrm{~g}$ portion of RMR powder was extracted with $10 \mathrm{~mL}$ of a phosphate-ethanol solution at 65 ${ }^{\circ} \mathrm{C}$. RMR powder was evaporated to dryness for determination of monacolin $\mathrm{K}$ and citrinin levels after removing the phosphate-ethanol solution $(n=3)$.

The coded points for this experimental design were shown in Tables $\mathbf{1}$ and $\mathbf{2}$. The model was evaluated in terms of statistically significant $\mathrm{r}^{2}$ and $p$ values.

\section{RESULTS AND DISCUSSION}

Dry Heating. Figure 1A shows that a dry-heating temperature below $140{ }^{\circ} \mathrm{C}$ did not cause a significant change in monacolin $\mathrm{K}$ and citrinin levels of RMR. However, increasing the temperature to $175^{\circ} \mathrm{C}$ resulted not only in a degradation of monacolin $\mathrm{K}$ but also the proportional increase of the citrinin level. Obviously, dry heating is not a suitable method for removing citrinin and retaining monacolin $\mathrm{K}$.

Wet Heating. Figure 1B shows that the citrinin level started to increase as the wet heat condition was increased to $90{ }^{\circ} \mathrm{C}$ and then decreased when the heat condition was increased to $175^{\circ} \mathrm{C}$. Extending the heating time resulted in increased citrinin levels and decreased monacolin K levels. Even when the heating temperature was increased to $175{ }^{\circ} \mathrm{C}$, citrinin was weakly removed, and the monacolin $\mathrm{K}$ retained was less than $15 \%$. This is why wet heating was considered to be a dangerous process for citrinin in previous study, because it may lead to the formation of citrinin H1. Highly toxic citrinin $\mathrm{H} 1$ was formed opon heating citrinin at $140{ }^{\circ} \mathrm{C}$ in the presence of water. The toxic compound was isolated from heated citrinin, and the structure was determined. The toxicity evaluated by cytotoxicity assay was 10 -fold higher on a weight basis than that of citrinin (15). Therefore, the results shown in Figure 1B clearly indicate that wet heating is also not suitable for the removal of citrinin and retention monacolin $\mathrm{K}$.

Alkaline Extraction. For all of the alkaline extractions, we found that sodium bicarbonate performed the best, with $34.5 \%$ citrinin and $88.5 \%$ monacolin $\mathrm{K}$ retained (Figure 2A). The factors of sodium bicarbonate extraction considered in this research included the solution volume and extraction times. Increasing the extraction time and repeated times were able to decrease the citrinin level, but the amount of monacolin $\mathrm{K}$ retained was slightly decreased as well. The highest $\mathrm{M} / \mathrm{C}$ ratio of 3.09 could be obtained by extraction 2 times with $5 \mathrm{~mL}$ of sodium bicarbonate $(0.25 \mathrm{M})$ for $60 \mathrm{~min}$ per time (Figure 2B). Although the alkaline solution could remove citrinin and have 
Table 3. Comparison of the Effect on Citrinin Retained, Monacolin K Retained, And M/C Ratio with the Optimal Condition of Each Method

\begin{tabular}{|c|c|c|c|c|}
\hline methods & conditions & citrinin retained (\%) & monacolin $\mathrm{K}$ retained $(\%)$ & $\mathrm{M} / \mathrm{C}$ ratio \\
\hline wet heating & $10 \mathrm{~mL}$ distilled water, $90^{\circ} \mathrm{C}, 20 \mathrm{~min}$ & 99.8 & 95.0 & 0.95 \\
\hline alkaline solution extraction & $5 \mathrm{~mL}$ sodium carbonate $(0.25 \mathrm{M}), 60 \mathrm{~min}, 30^{\circ} \mathrm{C}$ & 27.6 & 85.2 & 3.09 \\
\hline ethanol extraction & $10 \mathrm{~mL} 30 \%$ ethanol, $60 \mathrm{~min}, 65^{\circ} \mathrm{C}$ & 29.2 & 84.9 & 2.91 \\
\hline phosphate-ethanol extraction & $50 \%$ ethanol, $0.75 \%$ phosphate, $60 \mathrm{~min}, 65^{\circ} \mathrm{C}$ & 16.1 & 73.7 & 4.58 \\
\hline
\end{tabular}

Table 4. Analysis of Variance for the Production of Citrinin Retained, Monacolin K Retained, And M/C Ratio with Various Extraction Conditions ${ }^{a}$

\begin{tabular}{lcccc}
\hline & & \multicolumn{3}{c}{ sum of square } \\
\cline { 3 - 5 } \multicolumn{1}{c}{ source } & $d t^{\text {D }}$ & monacolin K retained & citrinin retained & $\mathrm{M} / \mathrm{C}$ ratio \\
\hline regression & 9 & 431.8 & 902.6 & 95.1 \\
residual & 5 & 23.7 & 131.1 & 29.5 \\
lack of fit & 3 & 21.5 & 126.0 & 27.0 \\
pure error & 2 & 2.2 & 5.1 & 2.4 \\
variability $\left(r^{2}\right)$ & & 0.95 & 0.87 & 0.80
\end{tabular}

\footnotetext{
${ }^{a}$ Analysis of variance from the SAS statistics system. ${ }^{b}$ Degrees of freedom. ${ }^{c}$ The ratio of monacolin $\mathrm{K}$ retained to citrinin retained.
}

a lesser effect on the retention of monacolin $\mathrm{K}$, the effect was not good enough to achieve a satisfying result with lesser citrinin and greater monacolin $\mathrm{K}$ retained.

Detoxification with Hydrogen Peroxide. Hydrogen peroxide was regarded as a citrinin breaker (11). Hajjaj et al. (2000) added medium fatty acid to the medium of Monascus species, which caused theMonascus species to form more hydrogen peroxide to detoxify citrinin (19). Furthermore, citrinin was found to be degraded and detoxified when treated with 5\% hydrogen peroxide (11). In this research, Figure 3 showed that citrinin could be removed at room temperature, and the amount of citrinin removed was increased with extended treating time. Treatment with $0.05 \%$ hydrogen peroxide was able to reduce citrinin by $54.5 \%$, but it also reduces the monacolin $\mathrm{K}$ level by $92.7 \%$. Increasing the concentration of hydrogen peroxide to $0.5 \%$ could significantly break citrinin as well as monacolin $\mathrm{K}$. On the basis of the result shown above, treatment with hydrogen peroxide was not suitable for reducing the citrinin level of RMR.

Ethanol Treatment. Monacolin K possesses more hydrophobic character than citrinin. Therefore, a low ethanol concentration is probably good enough to extract more citrinin and less monacolin $\mathrm{K}$ in RMR. As indicated in Figure $\mathbf{4 A}$, an ethanol concentration between 10 and $30 \%$ did not remarkably reduce the monacolin $\mathrm{K}$ level. In contrast, citrinin retention was significantly decreased with increasing ethanol concentration and treatment time. The results indicated that the $30 \%$ ethanol concentration was the optimal condition, reducing the citrinin level by $66.2 \%$ and retaining $88.6 \%$ of the monacolin $\mathrm{K}$ in RMR. Ethanol concentrations under $30 \%$ had difficulty removing citrinin, whereas more monacolin $\mathrm{K}$ was removed when the ethanol concentration was above $30 \%$. Therefore, the $30 \%$ ethanol concentration was used as the basal condition to further investigate optimization of the detoxification method (Figure 4B). Further study at various treated temperatures and times were performed to test the effect of $30 \%$ ethanol on removing citrinin and retaining monacolin $\mathrm{K}$. Increasing the heating temperature to $65^{\circ} \mathrm{C}$ had more effect on reducing the citrinin level of RMR, and the effect would be stronger with extended treating time. Treatment at $65^{\circ} \mathrm{C}$ for 60 min obtained a higher $\mathrm{M} / \mathrm{C}$ ratio in which monacolin $\mathrm{K}$ and citrinin levels of RMR were retained by $84.9 \%$ and $29.2 \%$, respectively.
Phosphate-Ethanol Extraction. In this study, the acidic condition was found to be effective in increasing the hydrophobic ability of monacolin $\mathrm{K}$ and citrinin, and the effect was more significant in monacolin $\mathrm{K}$ than in citrinin. Therefore, using a phosphate-ethanol solution should be able to extract more citrinin and less monacolin $\mathrm{K}$ from RMR. The result in Figure 5 proved the principle that the phosphate concentration significantly affected the effect of ethanol extraction by increasing the level of monacolin $\mathrm{K}$ retained. Although the $\mathrm{M} / \mathrm{C}$ ratio was increased to the highest level and more than $90 \%$ of the citrinin was extracted by $30 \%$ ethanol with less than $0.5 \%$ phosphate, less than $40 \%$ of the monacolin K of RMR would be retained at the same time. Extraction with $50 \%$ ethanol containing $0.75 \%$ phosphate was able to retain $16.1 \%$ citrinin and $73.7 \%$ monacolin $\mathrm{K}$, increasing the $\mathrm{M} / \mathrm{C}$ ratio to 4.58 . The results indicated that using a high concentration of acidic ethanol to extract RMR would decrease the citrinin level and increase the amount of monacolin $\mathrm{K}$ retained.

Comparison of the Detoxification Effect with Various Methods. Table 3 summarizes the optimal condition of each treatment based on above results. After comparing the results, we found that only the alkaline solution extraction, ethanol extraction, and phosphate-ethanol extraction showed some potential for removing citrinin and retaining monacolin $\mathrm{K}$. The $\mathrm{M} / \mathrm{C}$ ratio was used as a marker to select the optimal method. The results indicated that phosphate $(0.25 \%)$-ethanol $(50 \%)$ extraction exhibited the highest $\mathrm{M} / \mathrm{C}$ ratio at 4.58 . To improve and obtain the optimal phosphate-ethanol extraction method, response surface methodology (RSM) was further used to investigate the effect of extraction factors including ethanol concentration, phosphate concentration, and extraction time on removing citrinin and retaining monacolin $\mathrm{K}$.

Optimum Extraction Conditions Based on RSM. Design of Experiments and Model. RSM is a reliable and useful statistics methodology for investigating the optimal condition. RSM is usually used to investigate the effects of the condition factors on the changes of target product or markers through multiple views provided by a curve surface figure (5). This study used RSM to investigate optimum extraction conditions including three factors: ethanol concentration, phosphate concentration, and extraction time. The factors and coded values were shown in Tables $\mathbf{1}$ and $\mathbf{2}$.

Regression Equation, $r^{2}$ Value of Model. Data from 15 experiments were used to determine the regressional equation in which the factors were obtained from regressional analysis for the secondary metabolite concentrations:

Monacolin $\mathrm{K}$ retained $(\%)=79.1-4.66 \mathrm{X}_{1}+0.68 \mathrm{X}_{2}+1.22$ $\mathrm{X}_{3}+4.72\left(\mathrm{X}_{1}\right)^{2}-3.71\left(\mathrm{X}_{2}\right)^{2}+2.52\left(\mathrm{X}_{3}\right)^{2}-4.36 \mathrm{X}_{1} \mathrm{X}_{2}+$ $0.06 \mathrm{X}_{1} \mathrm{X}_{3}+0.31 \mathrm{X}_{2} \mathrm{X}_{3}$.

Citrinin retained $(\%)=28.8-8.73 \mathrm{X}_{1}-1.21 \mathrm{X}_{2}-3.34 \mathrm{X}_{3}$ $-4.26\left(\mathrm{X}_{1}\right)^{2}-1.21\left(\mathrm{X}_{2}\right)^{2}+3.10\left(\mathrm{X}_{3}\right)^{2}-3.90 \mathrm{X}_{1} \mathrm{X}_{2}+$ $0.56 \mathrm{X}_{1} \mathrm{X}_{3}-1.87 \mathrm{X}_{2} \mathrm{X}_{3}$

$\mathrm{M} / \mathrm{C}$ ratio $=2.75+1.99 \mathrm{X}_{1}+1.23 \mathrm{X}_{2}+0.38 \mathrm{X}_{3}+$ $1.91\left(\mathrm{X}_{1}\right)^{2}+1.28\left(\mathrm{X}_{2}\right)^{2}-1.42\left(\mathrm{X}_{3}\right)^{2}+2.33 \mathrm{X}_{1} \mathrm{X}_{2}+0.04 \mathrm{X}_{1} \mathrm{X}_{3}$ $+0.19 \mathrm{X}_{2} \mathrm{X}_{3}$. 
A.
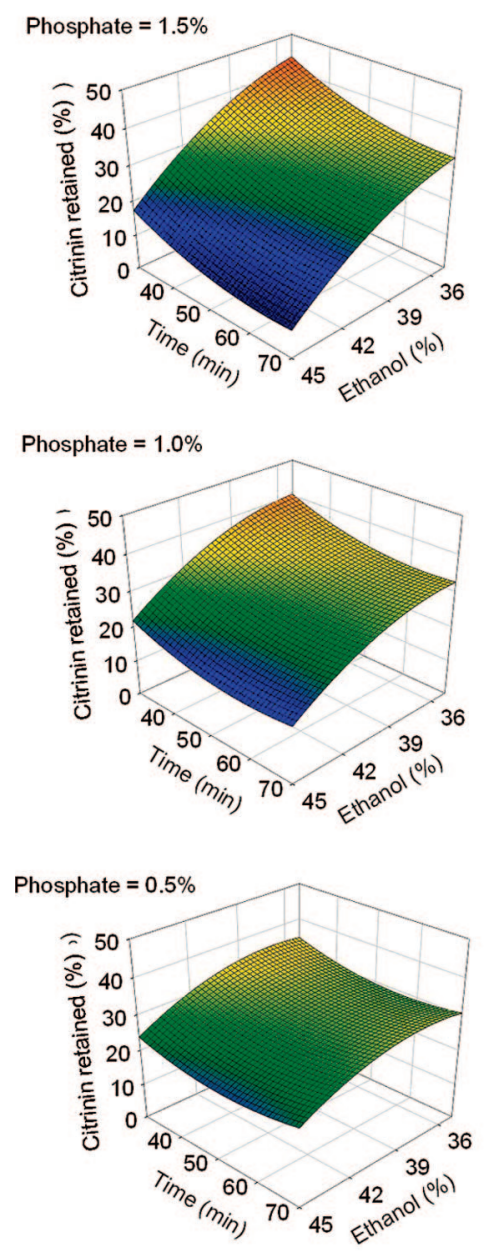

B.

Phosphate $=1.5 \%$

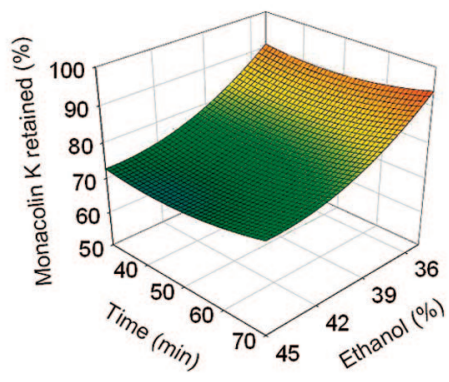

Phosphate $=1.0 \%$

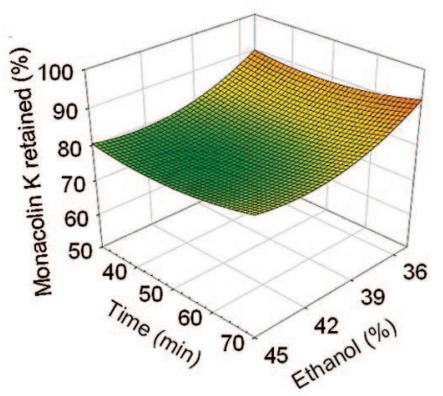

Phosphate $=0.5 \%$

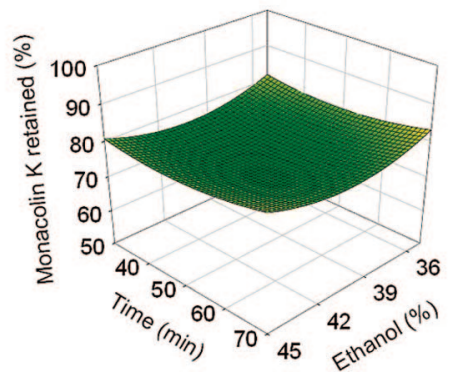

C.

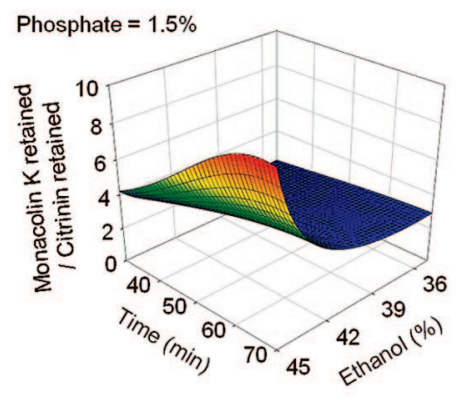

Phosphate $=1.0 \%$
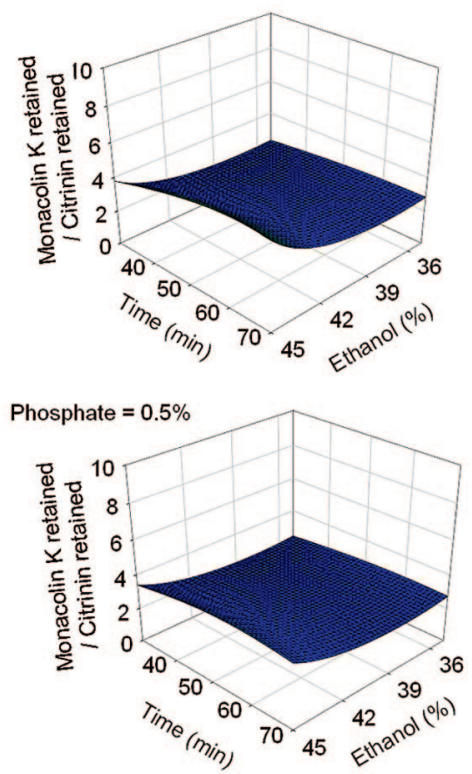

Figure 6. The response surface for citrinin retained, monacolin $\mathrm{K}$ retained, and $\mathrm{M} / \mathrm{C}$ ratio using phosphate-ethanol extraction with various ethanol concentration, phosphate concentration, and extraction time. A $1 \mathrm{~g}$ portion of RMR powder was extracted with $10 \mathrm{~mL}$ of a phosphate-ethanol solution at $65{ }^{\circ} \mathrm{C}$. RMR powder was evaporated to dryness for determination of monacolin $\mathrm{K}$ and citrinin levels after removing the phosphate-ethanol solution.

The variability in the responses was accounted for by the factor $\left(\mathrm{r}^{2}\right.$ value) for the model, and the data is given in Table 4. The $\mathrm{r}^{2}$ values of monacolin $\mathrm{K}$ level, citrinin level, and $\mathrm{M} / \mathrm{C}$ ratio were $0.95,0.87$, and 0.80 , respectively. Also, the $p$ value for the overall regression is significant at the $5 \%$ level, which indicates that the model is adequate in approximating the response surface of the experimental design.

The Effect of Extraction Condition on the Remanet of Citrinin. As shown in Figure 6A, the level of citrinin removed was sensitive to the ethanol concentration. Increasing the ethanol concentration significantly decreased the retained amount of citrinin as each extraction had the same ethanol concentration. This trend became more and more significant with increasing phosphate concentration. However, extraction time had less of an effect on changing the citrinin retained than ethanol concentration. The acidic condition was able to slightly stimulate the removal of citrinin because the hydrophobic character would be increased under acidic conditions. The amount of citrinin retained would be decreased to less than $10 \%$ when $45 \%$ ethanol containing $1.5 \%$ phosphate was used to extract RMR for 70 min.

The Effect of Extraction Condition on the Remanet of Monacolin K. As shown in Figure 6B, the retention of monacolin $\mathrm{K}$ was increased with increasing phosphate concentration. This indicates that the phosphate concentration is an important factor for repressing the extraction of monacolin K. Increasing the ethanol concentration resulted in a decrease in monacolin $\mathrm{K}$ retention because of the hydrophobic character of monacolin K. However, the extraction time would not cause a significant change in monacolin K retained. More than $90 \%$ monacolin $\mathrm{K}$ retention would be achieved when the extraction was carried out with $30 \%$ ethanol including more than $1.0 \%$ phosphate for $70 \mathrm{~min}$.

The Effect of Extraction Condition on M/C Ratio. As described above, the change of monacolin $\mathrm{K}$ retained exhibited a similar trend when compared to that of citrinin retained, because ethanol was able to extract these two compounds at the same time. Therefore, it was difficult to select the optimal condition from the reverse trends of RSM results. The M/C ratio was then considered to be the selection marker for the decision of the optimal result. The enhanced ratio implied that the extraction would result in an optimal RMR with higher monacolin $\mathrm{K}$ and lesser citrinin retained. Figure $6 \mathrm{C}$ shows that the $\mathrm{M} / \mathrm{C}$ ratio had no remarkable variation under low ethanol and phosphate concentrations at shorter extraction times. However, the $\mathrm{M} / \mathrm{C}$ ratio was significantly increased to more than 8.0 when the extraction condition was carried out with $45 \%$ ethanol and $1.5 \%$ phosphate for $70 \mathrm{~min}$.

Selection for the Optimal Extraction Condition through the Comprehensive Conclusion of RSM Results. Each surface 


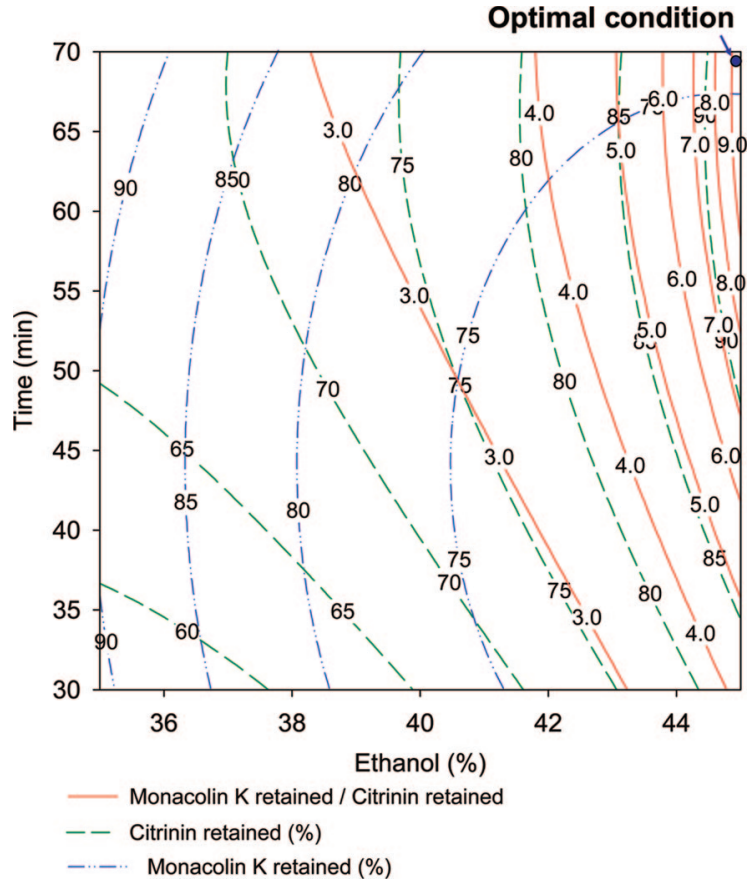

Figure 7. Overlapped contour plot for citrinin retained, monacolin $\mathrm{K}$ retained, and the $M / C$ ratio using phosphate-ethanol extraction with various ethanol concentrations and extraction time (phosphate concentration $=1.5 \%$ ).

Table 5. Effect of Extraction Conditions on the Citrinin Retained, Monacolin K Retained, and the M/C Ratio by Phosphate-Ethanol Extraction

\begin{tabular}{|c|c|c|c|c|c|c|}
\hline \multirow[b]{2}{*}{ methods } & \multicolumn{3}{|c|}{ extraction condition } & \multicolumn{3}{|c|}{ effector } \\
\hline & $\begin{array}{c}\text { ethanol } \\
(\%)\end{array}$ & $\begin{array}{c}\text { phosphate } \\
(\%)\end{array}$ & $\begin{array}{l}\text { extraction } \\
\text { time (min) }\end{array}$ & $\begin{array}{c}\text { monacolin } \\
\mathrm{K} \text { retained } \\
(\%)\end{array}$ & $\begin{array}{l}\text { citrinin } \\
\text { retained } \\
(\%)\end{array}$ & $\begin{array}{l}\mathrm{M} / \mathrm{C} \\
\text { ratio }^{a}\end{array}$ \\
\hline diluted ethanol & 30 & 0 & 60 & 84.9 & 29.2 & 2.91 \\
\hline $\begin{array}{l}\text { phosphate-ethanol } \\
\text { (control) }\end{array}$ & 50 & 1.0 & 60 & 73.7 & 16.1 & 4.57 \\
\hline $\begin{array}{l}\text { phosphate-ethanol } \\
\text { (RSM-Statistical } \\
\text { inference) }\end{array}$ & 45 & 1.5 & 70 & 75.9 & 7.9 & 9.61 \\
\hline $\begin{array}{l}\text { phosphate-ethanol } \\
\text { (RSM-Experimental } \\
\text { result) }^{a_{b}}\end{array}$ & 45 & 1.5 & 70 & 79.5 & 8.4 & 9.46 \\
\hline
\end{tabular}

\footnotetext{
${ }^{a}$ The ratio of monacolin $\mathrm{K}$ retained to citrinin retained. ${ }^{b}$ The optimal extraction
} condition based on RSM.

figure under the condition of $1.5 \%$ phosphate was overlapped, because $1.5 \%$ phosphate resulted in the highest $\mathrm{M} / \mathrm{C}$ ratio. As indicated on the overlapped surface figure shown in Figure 7, monacolin $\mathrm{K}$ and citrinin retained were increased toward the same trend. Although the extraction method could effectively removed citrinin, monacolin $\mathrm{K}$ was unable to escape the extraction. However, monacolin $\mathrm{K}$ retention did not show a sharp lowering trend when compared to the citrinin retention, even when the ethanol concentration was increased. Therefore, forsaking less monacolin $\mathrm{K}$ retention allowed us to remove more citrinin. The highest $\mathrm{M} / \mathrm{C}$ ratio can be considered as the optimal result in which the remanet of monacolin $\mathrm{K}$ and citrinin would be obtained by $75.9 \%$ and $7.9 \%$, respectively. As shown in Figure 7, the optimal extraction condition was $45 \%$ ethanol with $1.5 \%$ phosphate at an extraction time of $70 \mathrm{~min}$. The optimal condition of the phosphate-ethanol extraction based on the RSM results was further used to verify the remanet of monacolin $\mathrm{K}$ and citrinin. As shown in Table 5, 79.5\% monacolin $\mathrm{K}$ and $8.4 \%$ citrinin would be retained in the RMR powder after extraction using the RSM condition. The M/C ratio was also increased to 9.46 using the RSM condition.

Both monacolin $\mathrm{K}$ and citrinin are the derivatives of polyketide, so they possess similar structure and hydrophobic character. According to the results of various extraction methods and treatments, monacolin K and citrinin in RMR were difficult to be completely separated from each other. Therefore, how to maintain greater monacolin $\mathrm{K}$ was necessary when more citrinin was removed from RMR. However, the RSM result showed that increasing ethanol concentration, phosphate concentration, and extraction time would significantly increase the $\mathrm{M} / \mathrm{C}$ ratio. Phosphate increased the hydrophobic ability of monacolin K, which was able to prevent monacolin $\mathrm{K}$ of RMR from being extracted by the ethanol. Finally, the remarkable decrease of citrinin retained resulted in the increase of $\mathrm{M} / \mathrm{C}$ ratio. The phosphate-ethanol extraction also provided the advantages of being a rapid and simple process besides providing a higher $\mathrm{M} / \mathrm{C}$ ratio in RMR. Furthermore, the phosphate-ethanol extraction was a suitable method for the stability of monacolin $\mathrm{K}$ because the acidic condition would cause monacolin $\mathrm{K}$ to be stably maintained in the lactone form (16). Ethanol is also a safe solvent. Therefore, phosphate-ethanol extraction should be the most suitable and safe method for the postprocessing of RMR.

Although various methods used in this study seems feasible, many methods such as hydrogen peroxide and diluted ethanol extraction were unsuitable because of the significant decrease of monacolin K. However, sodium bicarbonate extraction was not effective enough at removing citrinin from RMR. Heating treatment would be the most unsuitable method because the citrinin was proportionally increased by wet heating, and monacolin $\mathrm{K}$ was completely broken at higher temperatures. However, the phosphate-ethanol extraction proved to be the optimum method in this study. This research was the first study to remove more citrinin and retain more monacolin $\mathrm{K}$ from RMR. The addition of phosphate resulted in more hydrophobic character in monacolin $\mathrm{K}$ than in citrinin. Therefore, ethanol could remove more citrinin but not more monacolin K. Importantly, RMR has been regarded as a functional food, so the extraction method should be safe and harmless for health. Phosphate-ethanol extraction, the optimal method, should be a harmless method for the safety of RMR. The optimum RSM condition was proven to have $79.5 \%$ monacolin $\mathrm{K}$ retained and 91.6\% citrinin removed in the final RMR. The color and texture did not show any change. In conclusion, the simple and rapid phosphate-ethanol extraction should provide RMR with more safety and acceptance.

\section{LITERATURE CITED}

(1) Endo, A. Monacolin K.; a new hypocholesterolemic agent produced by a Monascus species. J. Antibiot. (Tokyo) 1979, 32, 852-854.

(2) Blanc, P. J.; Laussac, J. P.; Le Bars, J.; Le Bars, P.; Loret, M. O.; Pareilleux, A.; Prome, D.; Prome, J. C.; Santerre, A. L.; Goma, G. Characterization of monascidin A from Monascus as citrinin. Int. J. Food Microbiol. 1995, 27, 201-213.

(3) Hajjaj, H.; Klaebe, A.; Loret, M. O.; Goma, G.; Blanc, P. J.; Francois, J. Biosynthetic pathway of citrinin in the filamentous fungus Monascus ruber as revealed by ${ }^{13} \mathrm{C}$ nuclear magnetic resonance. Appl. Environ. Microbiol. 1999, 65, 311-314.

(4) Su, Y. C.; Wang, J. J.; Lin, T. T.; Pan, T. M. Production of the secondary metabolites gamma-aminobutyric acid and monacolin K by Monascus. J. Ind. Microbiol. Biotechnol. 2003, 30, 41-46.

(5) Wang, J. J.; Lee, C. L.; Pan, T. M. Improvement of monacolin $\mathrm{K}$, gamma-aminobutyric acid and citrinin production ratio as a 
function of environmental conditions of. Monascus purpureus NTU 601. J. Ind. Microbiol. Biotechnol. 2003, 30, 669-676.

(6) Wang, J. J.; Lee, C. L.; Pan, T. M. Modified mutation method for screening low citrinin-producing strains of Monascus purpureus on rice culture. J. Agric. Food Chem. 2004, 52, 69776982.

(7) Chen, F.; Hu, X. Study on red fermented rice with high concentration of monacolin $\mathrm{K}$ and low concentration of citrinin. Int. J. Food Microbiol. 2005, 103, 331-337.

(8) Ciegler, A.; Vesonder, R. F.; Jackson, L. K. Produciton and biological activity of patulin and citrinin from Penicillium expansum. Appl. Environ. Microbiol. 1977, 33, 1004-1006.

(9) Krogh, P.; Hald, B.; Pedersen, E. J. Occurrence of ochratoxin A and citrinin in cereals associated with mycotoxic porcine nephropathy. Acta. Pathol. Microbiol. Scand. [B] Microbiol. Immunol. 1973, 81, 689-695.

(10) Muller, H. M.; Boley, A. Cold storage of wheat. 1. Ergosterol, ochratoxin A and citrinin after inoculation with Penicillium verrucosum. Arch. Tierernahr. 1992, 42, 351-363.

(11) Fouler, S. G.; Trivedi, A. B.; Kitabatake, N. Detoxification of citrinin and ochratoxin A by hydrogen peroxide. J. AOAC Int. 1994, 77, 631-637.

(12) Nelson, T. S.; Beasley, J. N.; Kirby, L. K.; Johnson, Z. B.; Ciegler, A. Effect of heat drying of corn on the extraction of citrinin. Poult. Sci. 1985, 64, 866-870.
(13) Kitabatake, N.; Trivedi, A. B.; Doi, E. Thermal-decomposition and detoxification of citrinin under various moisture conditions. J. Agric. Food Chem. 1991, 39, 2240-2244.

(14) Barber, J.; Cornford, J. L.; Howard, T. D.; Sharples, D. The structure of citrinin in vivo. J. Chem. Soc., Perkin Trans. 1987, 1, 2743-2744.

(15) Trivedi, A. B.; Hirota, M.; Doi, E.; Kitabatake, N. Formation of a new toxic compound, citrinin $\mathrm{H} 1$, from citrinin on mild heating in water. Perkin Trans. I 1993, 18, 2167-2171.

(16) Lee, C. L.; Wang, J. J.; Pan, T. M. Synchronous analysis method for detection of citrinin and the lactone and acid forms of monacolin $\mathrm{K}$ in red mold rice. J. AOAC Int. 2006, 89, 669-677.

(17) Box, G. E. P.; Behnken, D. W. Some new three level designs for the study of quantitative variable. Technometrics 1960, 2, 455463.

(18) Giovanni, M. Response surface methodology and product optimization. Food Technol. 1983, 37, 96-105.

(19) Hajjaj, H.; Klaebe, A.; Goma, G.; Blanc, P. J.; Barbier, E.; Francois, J. Medium-chain fatty acids affect citrinin production in the filamentous fungus Monascus ruber. Appl. Environ. Microbiol. 2000, 66, 1120-1125.

Received for review June 5, 2007. Revised manuscript received September 29, 2007. Accepted October 8, 2007.

JF071640P 